\title{
EVIDENCE FOR 5-HYDROXYTRYPTAMINE, SUBSTANCE P, AND THYROTROPIN-RELEASING HORMONE IN NEURONS INNERVATING THE PHRENIC MOTOR NUCLEUS ${ }^{1}$
}

\author{
JOSEPH R. HOLTMAN, JR., ${ }^{*, 2}$ WESLEY P. NORMAN, $\ddagger$ LANA SKIRBOLL, $\S$ \\ KENNETH L. DRETCHEN,* CLAUDIO CUELLO,\| THEO J. VISSER, \\ RICHARD A. GILLIS*
}

Departments of *Pharmacology and $\ddagger$ Anatomy, Georgetown University, Schools of Medicine and Dentistry, Washington, D. C. 20007; \$Laboratory of Clinical Sciences and Biology, Psychiatry Branch, National Institute of Mental Health, Bethesda, Maryland 20205; || Department of Anatomy, Oxford University, Oxford, England; $\uparrow$ Department of Internal Medicine III and Clinical Endocrinology, Medical Faculty, Erasmus University, Rotterdam, The Netherlands; and \#Department of Histology, Karolinska Institutet, Stockholm, Sweden

Received July 29, 1983; Revised October 31, 1983; Accepted November 4, 1983

\begin{abstract}
Retrograde tracing with a fluorescent dye (Fast Blue) combined with immunohistochemistry was used to identify putative neurotransmitter(s) at the phrenic motor nucleus in the cat. Fast Blue was injected bilaterally into the diaphragm of five cats, where each phrenic nerve enters the muscle. Seven days later the animals were perfusion fixed and tissue sections from the fourth, fifth, and sixth cervical spinal cord segments were analyzed using a fluorescence microscope. Retrogradely labeled fluorescent phrenic motor neuron cell bodies appeared in all of the segments but primarily in sections from the fifth segment. The same or adjacent transverse sections were then used for the demonstration of the distribution of the neurotransmitters 5 -hydroxytryptamine $(5-\mathrm{HT})$, substance $\mathrm{P}$, and thyrotropin-releasing hormone (TRH) in the area of the phrenic motor nucleus using the indirect immunofluorescence technique. The most conspicuous neurotransmitters found at the phrenic motor nucleus were 5-HT and substance P. We observed dense and diffuse fiber networks throughout the ventral horn which contains the phrenic motor nucleus. These fibers contained varicosities in close proximity to phrenic motor neurons. In addition to 5 - $\mathrm{HT}$ - and substance $\mathrm{P}$. containing nerve endings, some fibers containing TRH were also found in the area of the phrenic motor nucleus. These results are consistent with earlier physiological data suggesting that $5-\mathrm{HT}$, substance $\mathrm{P}$, and TRH are important neurotransmitters and/or neuromodulators involved in central control of respiration.
\end{abstract}

Our knowledge of central respiratory neurons is extensive with regard to their anatomical localization and their electrophysiological properties (Cohen, 1979; Mitchell and Berger, 1981). However, very little is known about the neurotransmitters of these neurons. One approach commonly used to obtain information about this point has been to inject a putative CNS neurotransmitter, an agonist or antagonist of the neurotransmitter or a pre-

\footnotetext{
This study was supported by National Heart, Lung and Blood Institute Grant HL 29562 to R. A. G. A preliminary report of these results was presented at the meeting of the Federation of American Societies for Experimental Biology, Chicago, IL, April 1983.

${ }^{2}$ To whom correspondence should be addressed, at the Department of Pharmacology, Georgetown University Schools of Medicine and Dentistry, 3900 Reservoir Road N.W., Washington, D. C. 20007.
}

cursor of the neurotransmitter into the brain, usually into the ventricular system, while monitoring some indices of respiratory activity. Using this approach, various neurotransmitters or putative neurotransmitters such as acetylcholine (Brimblecombe, 1977), the monoamines (Armijo et al., 1979; Lundberg et al., 1979; Mueller et al., 1980; Hedner et al., 1982), several amino acids (Sgaragli and Pavan, 1972; Yamada et al., 1981; Holtman et al., $1982,1983 \mathrm{~b}$ ), and several neuropeptides (Yamamoto et al., 1981; Hedner et al., 1982; Gillis et al., 1983; Holtman et al., 1983a, b, c) have been shown to cause CNSmediated changes in respiratory activity. Although these studies clearly show that endogenously occurring substances with suspected neurotransmitter or neuromodulator functions will affect respiration when injected into the CNS, little information has been obtained to localize 
the effect to any particular "respiratory center" or to involve the effect with any particular neuropathway.

A more promising approach to the study of neurotransmitters involved in the central control of respiration comes from investigations of the ventral surface of the medulla where drugs that antagonize the actions of known neurotransmitters were used. At this site, atropine and bicuculline were shown to depress and stimulate respiration, respectively (Dev and Loeschcke, 1979; Yamada et al., 1982). These data provided evidence for the presence of a tonic cholinergic and GABAergic system at the ventral surface of the medulla. Even this approach to studying neurotransmitters involved in central respiratory control is limited since the ventral surface of the medulla does not represent a defined anatomical substrate (i.e, nuclear group).

Because of the inherent limitations in previous approaches to studying the central neurotransmitters involved in controlling respiratory activity, we have used the technique of immunohistochemistry combined with retrograde tracing to determine which putative neurotransmitter(s) is(are) present at a defined anatomical substrate that represents the final outflow of respiratory activity to the periphery. Specifically, we have employed these techniques to determine the neurotransmitters at the phrenic motor nucleus in the cervical spinal cord of the cat.

\section{Materials and Methods}

Retrograde dye tracing procedure. Cats of either sex ( 2 to $4 \mathrm{~kg}$ ) were anesthetized with ketamine $(35 \mathrm{mg} / \mathrm{kg}$, i.m.). The inferior (i.e., abdominal) surface of the diaphragm was exposed by making a midline incision in the abdomen and retracting the abdominal wall and the liver. The retrograde fluorescent dye, Fast Blue (Bentivoglio et al., 1980) (5\% aqueous solution) was injected bilaterally into the area where each phrenic nerve enters the muscle. Five to ten injections of $10 \mu$ l were made on each side of the diaphragm using a Hamilton syringe. Animals were treated postoperatively with ampicillin $(500 \mathrm{mg}$, i.m.) to protect them against bacterial infection.

Following a 7-day survival time to allow for retrograde transport of the dye, each animal was prepared for transcardiac perfusion. For this procedure, each cat was anesthetized with sodium pentobarbital $(50 \mathrm{mg} / \mathrm{kg}$, i.p. $)$. The trachea was cannulated and the animal was artificially ventilated using room air. 'The chest was opened and a cannula was inserted transcardially into the aorta and secured by placing a ligature around the aorta. Initially, saline $(0.9 \% \mathrm{NaCl})$ was run through the cannula by gravity feed for $5 \mathrm{~min}$. This was followed by perfusion with $4 \%$ ice-cold paraformaldehyde in $0.1 \mathrm{M}$ phosphate buffer ( $\mathrm{pH} \mathrm{7.4)} \mathrm{for} 30 \mathrm{~min}$. The spinal cord was then removed and immersed in the same fixative for $90 \mathrm{~min}$. Next, the spinal cord was rinsed for $24 \mathrm{hr}$ in $0.1 \mathrm{M}$ phosphate buffer with $5 \%$ sucrose ( $\mathrm{pH} 7.4$ ). Sections of the spinal cord from the fourth, fifth, and sixth segments (C4-6) were then frozen and cut on a cryostat at $-20^{\circ} \mathrm{C}$ (section thickness of 10 to $14 \mu \mathrm{m}$ ). The sections were analyzed in a fluorescence microscope to visualize and photograph the retrogradely labeled phrenic motor neu- ron cell bodies containing Fast Blue. Photographs of dye containing phrenic motor neuron cell bodies were obtained using a Zeiss fluorescence microscope equipped for transmitting fluorescence with Schott UG1 and Zeiss 41 primary and secondary filters, respectively. Most sections were viewed and photographed unmounted, but some sections were mounted in xylene for the purpose of improving clarity of the labeled cells.

Immunohistochemistry procedure. After the Fast Bluelabeled phrenic motor neurons were photographed in a transverse section, the same or an adjacent transverse section was processed using the indirect immunofluorescence procedure of Coons (1958), as described in detail by Hökfelt et al. (1973). Sections were incubated with antisera to 5-hydroxytryptamine (5-HT) (1:400), substance $\mathrm{P}$ (1:200), and thyrotropin-releasing hormone (TRH) (1:200). Incubation took place in a humid atmosphere at $4^{\circ} \mathrm{C}$ for $24 \mathrm{hr}$, following which the sections were rinsed in $0.1 \mathrm{M}$ phosphate-buffered saline (PBS) ( $\mathrm{pH} 7.4)$ and incubated with rhodamine-conjugated sheep antirabbit or anti-rat (for substance $\mathrm{P}$ ) antibodies at $37^{\circ} \mathrm{C}$ for $30 \mathrm{~min}$. Sections were subsequently rinsed in PBS and mounted on slides using a mixture of glycerin and PBS (3:1). A Zeiss fluorescence microscope equipped for epifluorescence and filters to visualize rhodamine-induced fluorescence (Schott BP 546 and LP 590) were used to view the immunostain. All photographs were taken using Kodak High-speed 160 tungsten color film.

Control experiments were carried out as follows. The antisera adsorbed with an excess of the respective immunogen $(50 \mu \mathrm{g} / \mathrm{ml}$ of antiserum diluted $1: 10 ; 2$ to $4 \mathrm{hr}$ at room temperature during continuous shaking or 12 to $24 \mathrm{hr}$ at $4^{\circ} \mathrm{C}$ ) served as control sera. Furthermore, the antisera were analyzed with regard to cross-reactivity to the antigens studied; i.e., the 5-HT antiserum was adsorbed with an excess of TRH or substance P (as above), the TRH antiserum was adsorbed with an excess of substance $\mathrm{P}$ or 5 -HT (as above), and the substance $\mathrm{P}$ antiserum was adsorbed with an excess of TRH or 5-HT (as above).

The antisera used in these experiments were obtained from the following sources: rabbit antiserum to 5-HT was purchased from Immunonuclear Corp., Stillwater $\mathrm{MN}$; a monoclonal antiserum to synthetic substance $\mathrm{P}$ was generously supplied by Dr. C. Cuello (see Cuello et al., 1979); rabbit antiserum to synthetic TRH was supplied by Dr. 'I'. J. Visser (see Visser et al., 1977; Visser and Klootwijk, 1981).

Drugs and chemicals. The drugs and chemicals used in these experiments were obtained from the following sources: ketamine hydrochloride (Parke-Davis, Morris Plains, NJ), pentobarbital sodium (Abbott Laboratories, Chicago, IL), and ampicillin (Bristol Laboratory, Syracuse, NY). Fast Blue, a diamidino compound of True Blue (trans-1,2-bis-(5-amidino-2-benzofuranyl)-ethyl-2hydrochloride) was purchased from Dr. Illing, K.G. Makromolekulare Chemie, Grob-Umstadt, FRG. The source of 5-hydroxytryptamine was Sigma Chemical Co. (St. Louis, MO). Substance $P$ and thyrotropin-releasing hormone were obtained from Peninsula Laboratories (Belmont, CA). 


\section{Results}

In order to identify the neurotransmitter(s) at the phrenic motor nucleus, it was necessary to locate the phrenic motor neuron cell bodies in the spinal cord. This was done by injecting Fast Blue bilaterally into the diaphragm of the cat at the site where each phrenic nerve enters the muscle. This procedure was performed in five cats, and the location of injection sites from one animal is shown in Figure 1.

Following the intradiaphragmatic injections indicated in this figure, the phrenic motor nucleus cell bodies labeled with Fast Blue were found within the most ventral portion of the anterior horn of the gray matter in the fourth, fifth, and sixth segments of the cervical portion of the spinal cord. Most of the cell bodies were found within the fifth cervical spinal cord segment and were located approximately $3.5 \mathrm{~mm}$ below the dorsal cord surface and $0.9 \mathrm{~mm}$ lateral to the posterior median sulcus (Fig. 1). This location of the phrenic motor nucleus in the cat is in agreement with the findings of other investigators using nerve degeneration techniques (Keswani et al., 1954; Sterling and Kuypers, 1967) and retrograde tracing with horseradish peroxidase (Webber et al., 1979; Rikard-Bell and Bystrzycka, 1980).

The cell bodies were easily identified in the transverse sections (Figs. 2A, 3A, and $4 A$ ) and ranged in size and shape from fusiform (about $25 \mu \mathrm{m}$ ) to spherical (about $30 \mu \mathrm{m}$ ). This agrees with the morphology of these cells as described by Webber and colleagues (1979) and $\mathrm{Ri}$ kard-Bell and Bystrzycka (1980), using horseradish peroxidase to retrogradely label phrenic motor neurons. The cells appeared multipolar with processes arising from the cell bodies.

The same or adjacent transverse spinal cord sections containing the retrogradely labeled Fast Blue cell bodies were then used for observing the distribution of immunoreactivity in the phrenic motor nucleus. The most conspicuous neurotransmitter found at the phrenic motor nucleus was 5-HT. We observed a dense but diffuse fiber network throughout the area containing the phrenic motor nucleus (Fig. 2B). These fibers can be seen to contain varicosities and are in close proximity to phrenic motoneuron cell bodies. However, it was not possible to recognize fluorescent varicosities in immediate contact with the phrenic motoneurons.

Substance $\mathrm{P}$ and TRH immunoreactivity were also observed in the area of the phrenic motor nucleus (Figs. $3 B$ and $4 B$ ). Substance $\mathrm{P}$-immunoreactive fibers were almost as numerous as 5-HT-immunoreactive ones (cf. Figs. $3 B$ and $2 B$ ) and exhibited a similar pattern of distribution within the nucleus. Immunoreactive fibers for TRH were less numerous than those for either 5-HT or substance $\mathrm{P}$ and appeared to be more restricted to the phrenic motor neuron cell bodies (cf. Fig. $4 B$ with Figs. $2 B$ and $3 B$ ).

None of the immunoreactive structures described above could be observed after incubation with the respective control serum. Furthermore, the cross-reactivity experiments revealed that adsorption of the 5-HT antiserum with TRH or substance $\mathrm{P}$, of the TRH antiserum with substance $\mathrm{P}$ or $5-\mathrm{HT}$, and of the substance $\mathrm{P}$ antiserum with $\mathrm{TRH}$ or 5-HT in no way influenced the intensity or the distribution of fluorescent structures.

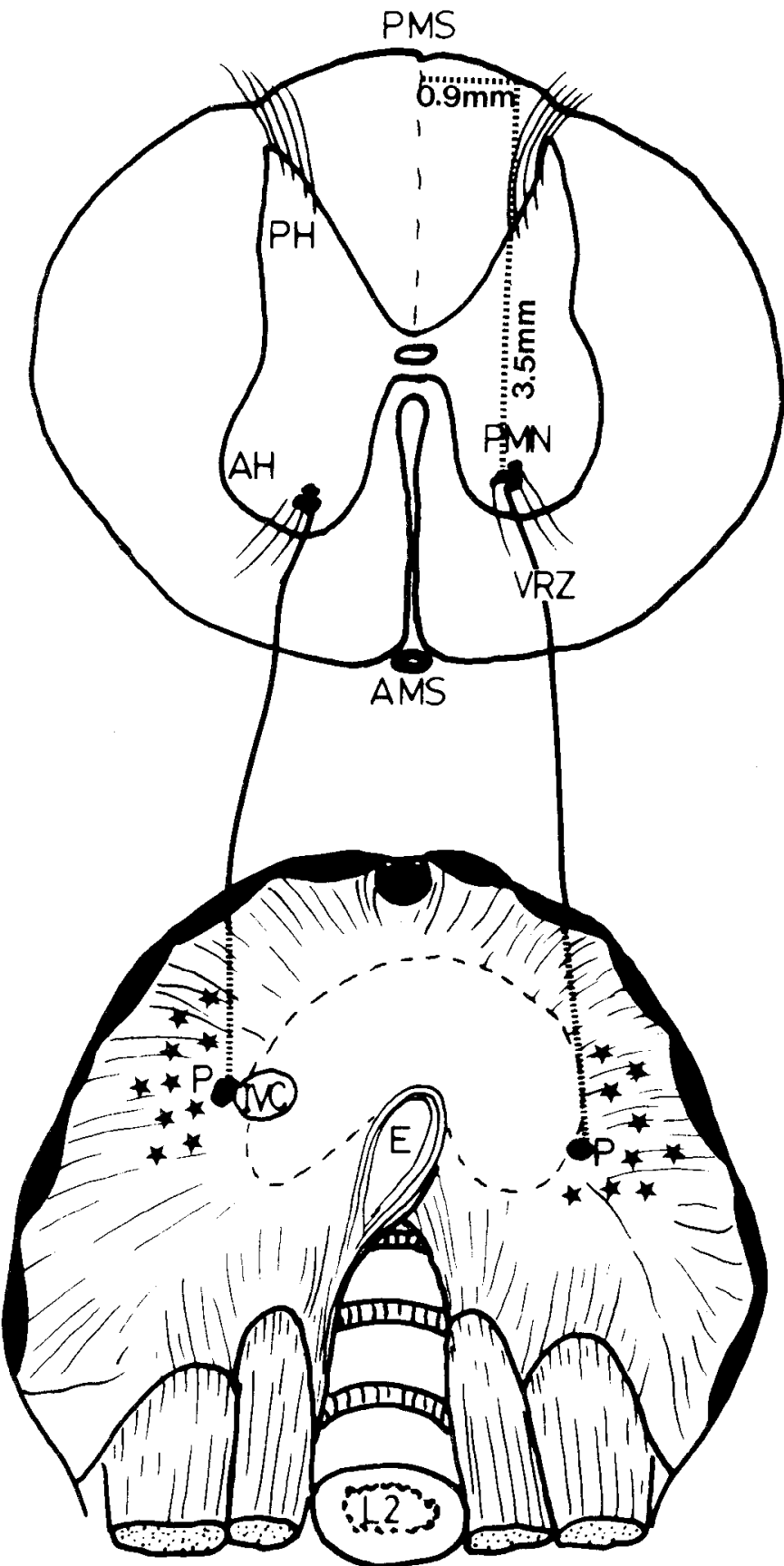

Figure 1. Location of retrogradely labeled phrenic motor neuron cell bodies in the cervical spinal cord following bilateral injection of Fast Blue into the diaphragm of the cat. Top, Line drawing of a tranverse section from the fifth cervical segment of the spinal cord. Phrenic motor neuron cell bodies labeled with Fast Blue were localized in the ventral portion of the anterior horn. Bottom, Line drawing of the abdominal surface of the diaphragm. Bilateral injections (stars) of Fast Blue were made in the area where the phrenic nerve enters the muscle. $A H$, anterior horn; $A M S$, anterior median sulcus; $E$, esophagus; $I V C$, inferior vena cava; $L 2$, second lumbar vertebra; $P$, phrenic nerve; $P H$, posterior horn; $P M N$, phrenic motor nucleus; $P M S$, posterior median sulcus; VRZ; ventral root zone.

\section{Discussion}

The purpose of our study was to use the techniques of immunohistochemistry combined with retrograde tracing to determine the putative neurotransmitter(s) present at the phrenic motor nucleus. Our data indicate that 

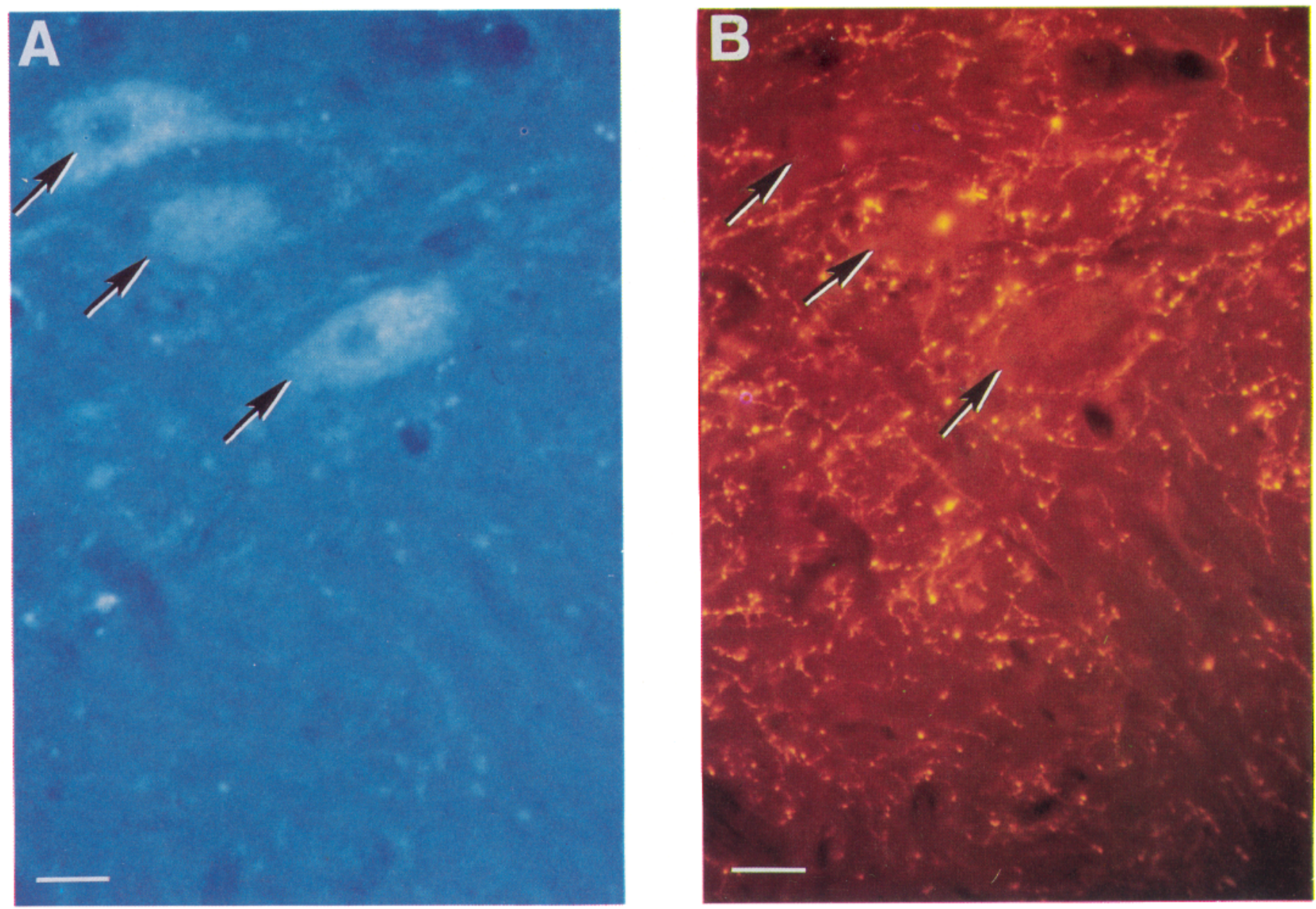

Figure 2. Fluorescence $(A)$ and immunofluorescence $(B)$ micrographs of the phrenic motor nucleus in a transverse section of the fifth cervical segment of the spinal cord after injection of Fast Blue into the diaphragm and after incubation with 5-HT antiserum. $A$ and $B$ represent adjacent $14-\mu \mathrm{m}$ sections. $A$, Fluorescent (icy-white) phrenic motor neuron cell bodies retrogradely labeled with Fast Blue. $B$, Immunofluorescent (yellow) fibers containing 5-HT around the phrenic motor neuron cell bodies and present in the surrounding neuropil. The arrowheads identify the same phrenic motor neurons in each micrograph. Bar $=32 \mu \mathrm{m}$.

5-HT, substance $\mathrm{P}$, and TRH are all present at this nucleus. Indeed, dense fiber networks containing each of these substances were observed surrounding retrogradely labeled cell bodies of the phrenic motor nucleus. These fiber networks contained varicosities suggestive of a neurotransmitter and/or neuromodulator role for 5-HT, substance $\mathrm{P}$, and TRH in respiration.

The finding that $5-\mathrm{HT}$, substance $\mathrm{P}$, and TRH were present at the phrenic motor nucleus is not surprising. Originally, 5-HT-containing fibers were demonstrated in the spinal cord with formaldehyde-induced fluorescence (Dahlström and Fuxe, 1965), and these findings were recently confirmed using immunohistochemistry and antisera to 5-HT (Steinbusch et al., 1978; Hökfelt et al., 1978). Subsequently, several investigators have reported that all three substances exist in the ventral horn of the rat spinal cord (Hökfelt et al., 1975a, b, 1978; Johansson et al., 1981; Gilbert et al., 1982). In fact, fibers containing 5-HT, substance P, and TRH have been described as surrounding somatic motor neurons in the cervical, thoracic, and lumbar cord (Hökfelt et al., 1978; Johansson et al., 1981; Gilbert et al., 1982). However, the presence of all three of these has not been related to specific motor outflow. Based on our findings, we suggest that $5-\mathrm{HT}$, substance $\mathrm{P}$, and TRH may be important for the control of motor outflow to the diaphragm.

The origin of the immunoreactive fibers in the phrenic nucleus was not examined in this study. However, data obtained by other investigators and data of our own suggest a supraspinal site. Regarding the origin of $5-\mathrm{HT}$ in the ventral horn of the spinal cord, Dahlström and Fuxe (1965) have shown with histofluorescence techniques that the medullary raphe nuclei are the main source of 5-HT cell bodies in the brain. Specifically, fibers of 5-HT neurons of the raphe pallidus and obscurus descend in the ventral and ventral lateral funiculi to innervate the ventral horn of the spinal cord in the cat (Martin et al., 1978; Basbaum and Fields, 1979; Björklund and Skagerberg, 1982).

Hökfelt and colleagues (1978) and Johansson and coworkers (1981), who used immunohistochemical techniques, and Gilbert and colleagues (1982), who used both immunohistochemical and biochemical methods, have demonstrated the coexistence of either substance $\mathrm{P}$ or TRH or both substance P and TRH in 5-HT neurons descending to the ventral horn of the cervical spinal cord in the rat. Immunohistochemical staining for 5-HT, substance $\mathrm{P}$, and TRH showed that all three substances had 

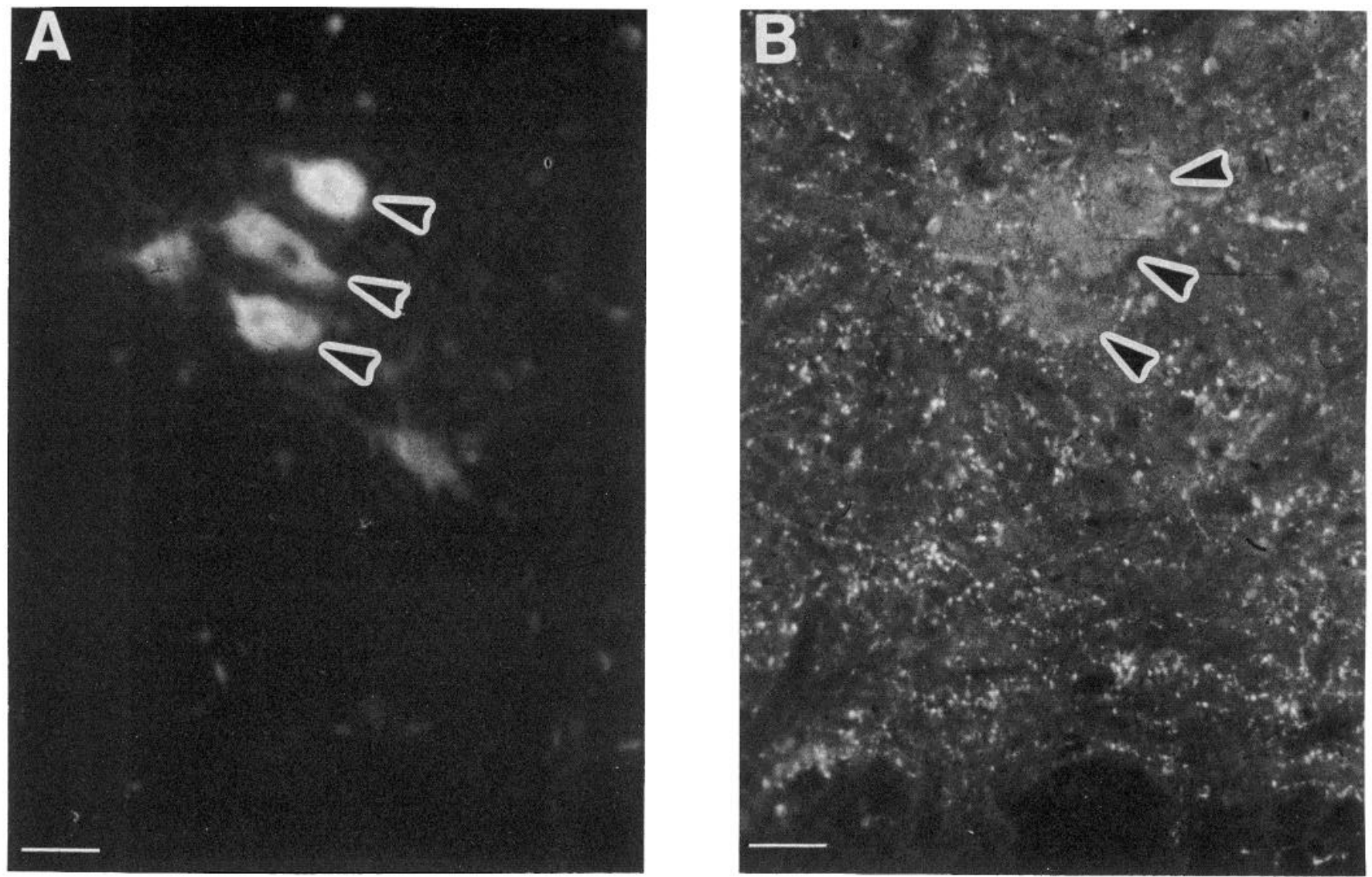

Figure 3. Fluorescence $(A)$ and immunofluroescence $(B)$ micrographs of the phrenic motor nucleus in a transverse section of the fifth cervical segment of the spinal cord after injection of Fast Blue into the diaphragm and after incubation with substance $\mathrm{P}$ antiserum. $A$ and $B$ represent adjacent $14-\mu \mathrm{m}$ sections. $A$, Fluorescent phrenic motor neuron cell bodies retrogradely labeled with Fast Blue. $B$, Immunofluorescent fibers containing substance $\mathrm{P}$ around the phrenic motor neurons and in the surrounding neuropil. The arrowheads identify the same phrenic motor neuron cell bodies in each micrograph. Bar $=52 \mu \mathrm{m}$.

a similar distribution in the ventral horn of the cervical cord. After treatment with 5,7-dihydroxytryptamine, neuronal elements containing 5-HT and TRH degenerated and disappeared from this part of the spinal cord in parallel with one another. Biochemical measurements of 5 -HT, substance P, and TRH in the spinal cord after treatment with 5,7-dihydroxytryptamine confirmed that these three substances were depleted from the ventral horn of the cervical cord. These results are consistent with the conclusion that 5-HT and one or both of these peptides in the ventral horn of the cervical spinal cord originate from the same neuron, specifically from descending 5-HT bulbospinal nerve fibers. However, it should be noted that not all of the substance $\mathrm{P}$ and TRH disappeared following treatment with the serotonin neurotoxin. The lack of a complete disappearance of substance $\mathrm{P}$ and TRH in the ventral horn of the cervical spinal cord following treatment with the 5-HT neurotoxin may indicate that the treatment has not been fully effective and/or that these peptides may also be present in some neurons without 5-HT.

Our data obtained by injecting the retrogradely transported fluorescent dye, propidium iodide (Kuypers et al., 1979), into the phrenic motor nucleus of the cat agree with the above findings. We found propidium iodideretrogradely labeled cell bodies in the nucleus raphe pallidus and obscurus (Holtman et al., 1983c). In addition, using immunohistochemical techniques, we have recently demonstrated that cell bodies in the raphe pallidus contain $5-\mathrm{HT}$, substance $\mathrm{P}$, and TRH and that some of these cells contain 5-HT and one or both of these peptides (J. R. Holtman, Jr., unpublished data). Furthermore, in a parallel study to the present one in the cat, it has been established by combined retrograde tracing and immunohistochemistry that 5-HT, substance $\mathrm{P}$, and TRH coexist in descending bulbospinal systems (T. Hökfelt, manuscript in preparation).

Other sites that should be considered as the origin of the immunoreactive fibers in the phrenic motor nucleus are the supraspinal inputs to this nucleus as described by earlier neurophysiological studies. These consist of the ventrolateral nucleus of the tractus solitarii (von Euler et al., 1973), the nucleus retroambigualis (Merrill, 1974), and the nucleus interfascicularis hypoglossi (Loewy and McKellar, 1981). The first two sites refer to the dorsal respiratory group and ventral respiratory group of neurons, respectively (Mitchell, 1977). The third site corresponds to Loeschcke's area on the ventral surface of the medulla in the cat (Loeschcke et al., 1970). It is clear from recent data published in the cat that there are no serotonergic cell bodies in the dorsal respiratory group of neurons (Wiklund et al., 1981; Maley and Elde, 

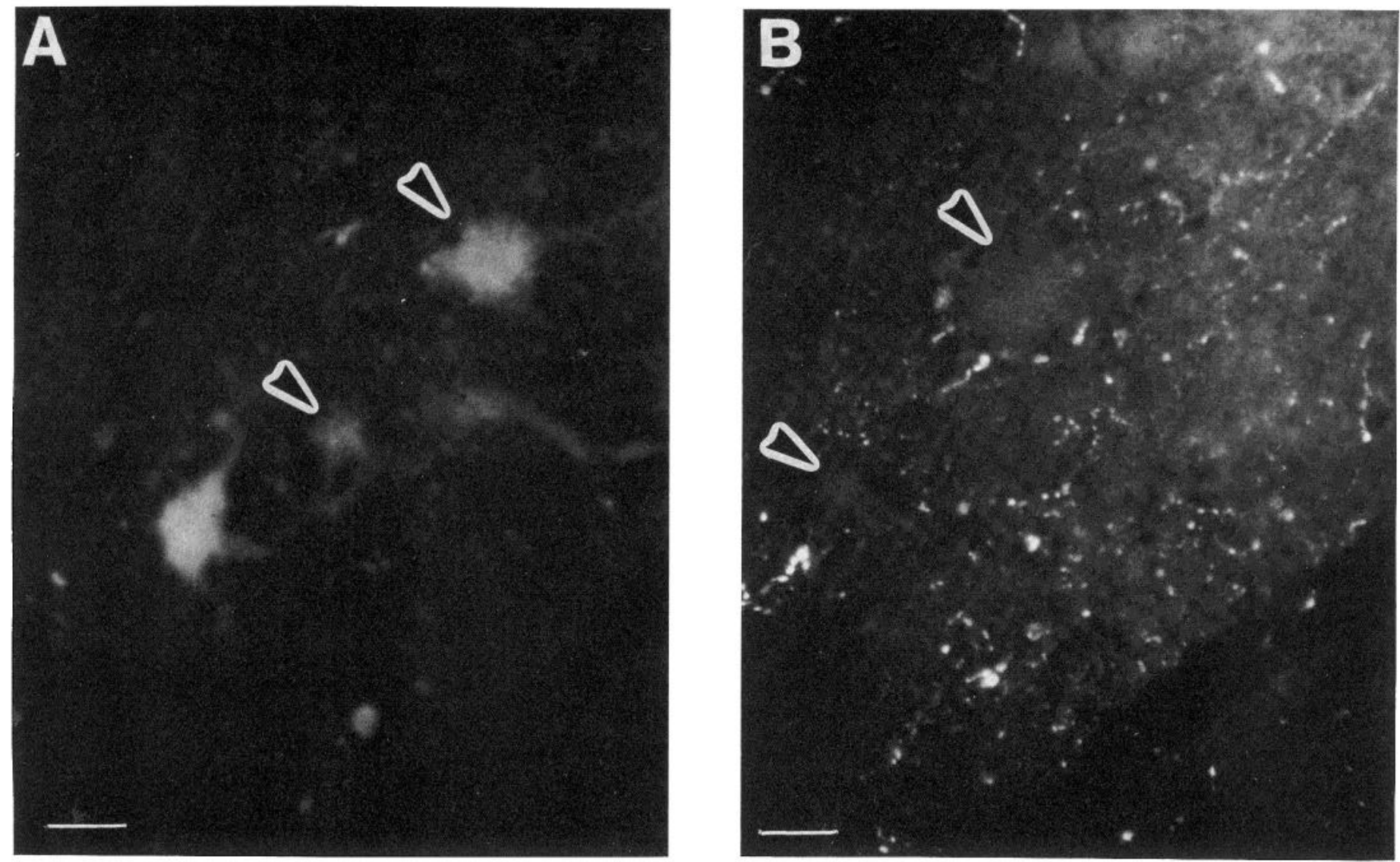

Figure 4. Fluorescence $(A)$ and immunofluorescence $(B)$ micrographs of the phrenic motor nucleus in a transverse section of the fifth cervical segment of the spinal cord after injection of Fast Blue into the diaphragm and after incubation with TRH antiserum. $A$ and $B$ represent adjacent $14-\mu \mathrm{m}$ sections. $A$, Fluorescent phrenic motor neuron cell bodies retrogradely labeled with Fast Blue. $B$, Immunofluorescent fibers containing TRH around the phrenic motor neuron cell bodies and present in the surrounding neuropil. The arrowheads identify the same phrenic motor neurons in each micrograph. Bar $=52 \mu \mathrm{m}$.

1982) and few, if any, in the ventral respiratory group of neurons (Maley and Elde, 1982). Data obtained from the rat indicate that cells of the nucleus interfascicularis hypoglossi do contain all three substances (Johansson et al., 1981). However, these cells do not appear to send projections to the phrenic motor nucleus as pretreatment of rats with 5,7-dihydroxytryptamine does not prevent labeling of the phrenic nucleus with tritiated amino acids after microinjection into the nucleus interfascicularis hypoglossi (A. D. Loewy, personal communication). In addition, no cell bodies were labeled with propidium iodide in this nucleus following iontophoresis of this dye into the phrenic motor nucleus (Holtman et al., 1983c).

The presence of 5-HT, substance $\mathrm{P}$, and TRH at the final output site from the CNS to the diaphragm raises the question as to what role these substances have at the phrenic motor nucleus in the control of breathing. To our knowledge no data exist on the effect of iontophoresis of any of these substances on the excitability of phrenic motor neurons. However, there are data describing the effects of 5-HT, substance P, and TRH on the excitability of other motor neurons in the spinal cord. Each of these substances has been shown to increase motoneuron excitability in the spinal cord (Myslinski and Anderson, 1977; Cooper and Boyer, 1978; Nicoll, 1978; Barbeau and Bédard, 1979, 1981a, b; White and Neuman, 1980; and
Matsumiya, 1981; Ono and Fukuda, 1982). The increase in excitability was characteristically similar for all three substances. That is, the increase was manifested by either an increase in the amplitude of an electrically evoked ventral root motor neuron potential or a potentiation of glutamate-evoked motor neuron activity. Rarely was there any evidence that 5 - $\mathrm{HT}$, substance P, or TRH produced direct excitation of motor neurons as was characteristically observed with glutamate. These results suggest that $5-\mathrm{HT}$, substance $\mathrm{P}$, and TRH may act as neuromodulators which enhance the effects of excitatory inputs to motor neurons. An excitatory action of these substances on phrenic motor neurons fits with at least some of the reported effects of these agents on respiratory activity. For example, central administration of 5-HT or 5-hydroxytryptophan causes respiratory stimulation (Eldridge et al., 1979; Millhorn et al., 1982). In addition, central administration of substance $\mathrm{P}$ and TRH have been reported to cause enhancement of respiratory activity (Yamamoto et al., 1981; Hedæer et al., 1981). Finally, our preliminary data obtained with electrical stimulation of raphe pallidus in the cat indicate that an increase in the activity of these neurons results in an increase in phrenic nerve activity (Dretchen et al., 1983). It is possible that the respiratory effects of these substances and raphe stimulation are a manifestation of a 
neuromodulator function which results in enhancement of the effects of excitatory inputs on phrenic motor neurons.

In summary, our data indicate that fiber networks containing 5-HT, substance $P$, and TRH surround retrogradely labeled cell bodies of the phrenic motor nucleus of the cat. The origin of these fibers is probably the nucleus raphe pallidus and obscurus, and it is very likely that all three substances are contained in many of the same neurons. The role of this raphe-spinal projection may be to regulate the excitability of phrenic motor neurons to the effects of excitatory inputs from medullary respiratory centers.

\section{References}

Armijo, J. A., A. Mediavilla, and J. Florez (1979) Inhibition of the activity of the respiratory and vasomotor centers by centrally administered 5-hydroxytryptamine in cats. Rev. Esp. Fisiol. 35: 219-228.

Barbeau, H., and P. Bédard (1979) Similar motor effects of 5HT and TRH in chronic spinal rats and monkeys. Soc. Neurosci. Abstr. 5: 1848.

Barbeau, H., and P. Bédard (1981a) Denervation supersensitivity to 5-hydroxytryptophan in rats following spinal transection and 5,7-dihydroxytryptamine injection. Neuropharmacology 20: 611-616.

Barbeau, H., and P. Bédard (1981b) Similar motor effects of 5 $\mathrm{HT}$ and TRH in rats following chronic spinal transection and 5,7-dihydroxytryptamine injection. Neuropharmacology 20: $477-481$.

Basbaum, A. I., and H.L. Fields (1979) The origin of descending pathways in the dorsolateral funiculus of the spinal cord of the cat and rat: Further studies on the anatomy of pain modulation. J. Comp. Neurol. 187: 513-532.

Bell, J. A., and T. Matsumiya (1981) Inhibitory effects of dorsal horn and excitant effects of ventral horn intraspinal microinjections of norepinephrine and serotonin in the cat. Life Sci. 29: 1507-1514.

Bentivoglio, M., H. G. J. M. Kuypers, C. E. Catsman-Berrevoets, $H$. Loewe, and O. Dann (1980) Two new fluorescent retrograde neuronal tracers which are transported over long distances. Neurosci. Lett. 18: 25-30.

Björklund, A., and G. Skagerberg (1982) Descending monoaminergic projections to the spinal cord. In Brain Stem Control of Spinal Mechanisms, B. Sjolund and A. Björklund, eds., pp. 55-88, Elsevier Biomedical Press, Amsterdam.

Brimblecombe, R. W. (1977) Drugs acting on central cholinergic mechanisms and affecting respiration. Pharmacol Ther. Part B Gen. Syst. Pharmacol. 3: 65-74.

Cohen, M. I. (1979) Neurogenesis of respiratory rhythm in the mammal. Physiol. Rev. 59: 1105-1173.

Coons, A. H. (1958) Fluorescent antibody methods. In General Cytochemical Methods, J. F. Danielli ed., pp. 399-422, Academic Press, Inc., New York.

Cooper, B. R., and C. E. Boyer (1978) Stimulant action of thyrotropin-releasing hormone on cat spinal cord. Neuropharmcology 17: 153-156.

Cuello, A.C., G. Galfre, and C. Milstein (1979) Detection of substance $P$ in the central nervous system by a monoclonal antibody. Proc. Natl. Acad. Sci. U. S. A. 76: 3532-3536.

Dahlström, A., and K. Fuxe (1965) Evidence for the existence of monoamine neurons in the central nervous system. II. Experimentally-induced changes in the intraneuronal amine levels of bulbospinal neuron systems. Acta Physiol. Scand. Suppl. 247: 5-36.

Dev, N. B., and H. H. Loeschcke (1979) A cholinergic mechanism involved in the respiratory chemosensitivity of the medulla oblongata in the cat. Pflugers Arch. 379: 29-36.

Dretchen, K. L., J. R. Holtman, Jr., B. L. Hamilton, W. P. Norman, and R. A. Gillis (1983) Effect of electrical stimulation of raphe nuclei on spontaneous phrenic nerve activity. Fed. Proc. 42: 331

Eldridge, F. L., D. W. Millhorn, and T. G. Waldrop (1979) Respiratory effect of centrally injected serotonin. Physiologist 22: 33 .

Gilbert, R. F. T., P. C. Emson, S. P. Hunt, G. W. Bennett, C. A. Marsden, B. E. B. Sandberg, H. W. M. Steinbusch, and A. A. J. Verhofistad (1982) The effects of monoamine neurotoxins on peptides in the rat spinal cord. Neuroscience 7:6987.

Gillis, R.A., J.A. Quest, F. D. Pagani, J. Dias Souza, A. M. T. Da Silva, R. T. Jensen, T.Q. Garvey, III. and P. Hamosh (1983) Activation of CNS cholecystokinin receptors stimulate respiration in the cat. J. Pharmacol. Exp. Ther. 224: 408-414.

Hedner, J.,T. Hedner, J. Jonason, and D. Lundberg (1981) Central respiratory stimulant effect by thyrotropin releasing hormone in the rat. Neurosci. Lett. 25: 317-320.

Hedner, J., T. Hedner, J. Jonason, and D. B. A. Lundberg (1982) Evidence for a dopamine interaction with the central respiratory control system in the rat. Eur. J. Pharmacol. 81: 603-615.

Hökfelt, T., K. Fuxe, M. Goldstein, and T. H. Joh (1973) Immunohistochemical localization of three catecholamine synthesizing enzymes: Aspects on methodology. Histochemie 33: $231-254$.

Hökfelt, T., K. Fuxe, O. Johansson, S. Jeffcoate, and N. White (1975a) Distribution of thyrotropin-releasing hormone (TRH) in the central nervous system as revealed with immunohistochemistry. Eur. J. Pharmacol. 34: 389-392.

Hökfelt, T., K. Fuxe, O. Johansson, S. Jeffcoate, and N. White (1975b) Thyrotropin-releasing hormone (TRH)-containing nerve terminals in certain brain stem nuclei and in the spinal cord. Neurosci. Lett. 1: 133-139.

Hökfelt, T., A. Ljungdahl, H. Steinbusch, A. Verhofstad, G. Nilsson, B. Pernow, and M. Goldstein (1978) Immunohistochemical evidence of substance P-like immunoreactivity in some 5 hydroxytryptamine-containing neurons in the rat central nervous system. Neuroscience 3: 517-538.

Holtman, J. R., Jr., A. Buller, P. Hamosh, A. M. T. Da Silva, and R. A. Gillis (1982) Respiratory depression produced by glycine injected into the cisterna magna of cats. Neuropharmacology 21: 1223-1225.

Holtman, J. R., Jr., A. Buller, A. M. T. Da Silva, P. Hamosh, and R. A. Gillis (1983a) Respiratory depression produced by centrally administered taurine in the cat. Life Sci. 32: 23132420.

Holtman, J. R., Jr., R. T. Jensen, A. Buller, P. Hamosh, A. M. T. Da Silva, and R. A. Gillis (1983b) Central respiratory stimulant effect of bombesin in the cat. Eur. J. Pharmacol. 90: 449-451.

Holtman, J. R., Jr., W. P. Norman, and R. A. Gillis (1983c) Projections from the raphe nuclei to the phrenic motor nucleus in the cat. Neurosci. Lett., in press.

Johansson, O., T. Hökfelt, B. Pernow, S. L. Jeffcoate, N. White, H. W. M. Steinbusch, A. A. J. Verhofstad, P. C. Emson, and E. Spindel (1981) Immunohistochemical support for three putative transmitters in one neuron: Coexistence of 5-hydroxytryptamine, substance $\mathrm{P}$, and thyrotropin releasing hormone-like immunoreactivity in medullary neurons projecting to the spinal cord. Neuroscience 6 : 1857-1881.

Keswani, N. H., R. A. Groat, and W. H. Hollinshead (1954) The phrenic nucleus in the spinal cord of the cat. J. Anat. Soc. India 3: 82-89.

Kuypers, H. G. J. M., M. Bentivoglio, D. Van Der Kooy, and C. E. Catsman-Berrevoets (1979) Retrograde transport of 
bisbenzimide and propidium iodide through axons to their parent cell bodies. Neurosci. Lett. 12: 1-7.

Loeschcke, H. H., J. de Lattre, M. E. Schlafke, and C. O. Trouth (1970) Effects on respiration and circulation of electrically stimulating the ventral surface of the medulla oblongata. Respir. Physiol. 10: 184-197.

Loewy, A. D., and S. McKellar (1981) Serotonergic projections from the ventral medulla to the intermediolateral cell column in the rat. Brain Res. 211: 146-152.

Lundberg, D. B. A., G. R. Breese, and R. A. Mueller (1979) Dopaminergic interaction with the respiratory control system in the rat. Eur. J. Pharmacol. 54: 153-159.

Maley, B., and R. Flde (1982) Immunohistochemical localization of putative neurotransmitters within the feline nucleus tractus solitarii. Neuroscience 7: 2469-2490.

Martin, R. F., L. M. Jordan, and W. D. Willis (1978) Differential projections of cat medullary raphe neurons demonstrated by retrograde labelling following spinal cord lesions. J. Comp. Neurol. 182: 77-88.

Merrill, E. G. (1974) Finding a respiratory function for the medullary respiratory neurons. In Essays on the Nervous System, R. Bellairs and E. G. Gray, eds., pp. 451-486, Oxford University Press (Claredon), New York.

Millhorn, D. E., F. L. Eldridge, T. G. Waldrop, and L. E. Klinger (1982) Effects of centrally and peripherally administered 5-hydroxytryptophan (5-HTP) on respiration. Fed. Proc. 41: 1379.

Mitchell, R. A. (1977) Location and function of medullary respiratory neurons. Am. Rev. Respir. Dis. 115: 212-216.

Mitchell, R. A., and A. J. Berger (1981) Neural regulation of breathing. In Regulation of Breathing, T. F. Ilornbein, ed., pp. 541-620, Marcel Dekker, Inc., New York.

Mueller, R. A., D. Lundberg, and G. R. Breese (1980) Evidence that respiratory depression by serotonin agonists may be exerted in the central nervous system. Pharmacol. Biochem. Behav. 13: 247-255.

Myslinski, N. R., and E. G. Anderson (1977) The effects of serotonin precursors on alpha- and gamma-motoneuron activity. J. Pharmacol. Exp.Ther. 204: 19-26.

Nicoll, R. A. (1978) The acton of thyrotropin releasing hormone, substance $\mathrm{P}$ and related peptides on frog spinal motoneurons. J. Pharmacol. Exp. Ther. 207: 817-824.

Ono, H., and H. Fukuda (1982) Ventral root depolarization and spinal reflex augmentation by a TRH analog in rat spinal cord. Neuropharmacology 21: 731-744.

Rikard-Bell, G. C., and E. K. Bystrzycka (1980) Localization of phrenic motor nucleus in the cat and rabbit studied with horseradish peroxidase. Brain Res. 194: 479-483.

Sgaragli, G., and F. Pavan (1972) Effects of amino acid compounds injected into cerebrospinal fluid spaces, on colonic temperature, arterial blood pressure and behavior of the rat. Neuropharmacology 11: 45-56.

Steinbusch, H. W. M., A. A. J. Verhofstad, and H. W. J. Joosten (1978) Localization of serotonin in the central nervous system by immunohistochemistry: Description of specific and sensitive technique and some applications. Neuroscience 3 : 811-819.

Sterling, P., and H. G. J. M. Kuypers (1967) Anatomical organization of the brachial spinal cord of the cat. II. The motoneuron plexus. Brain Res. 4: 16-32.

Visser, T. J., and W. Klootwijk (1981) Approaches to a markedly increased sensitivity of the radioimmunoassay for thyrotropin-releasing hormone by derivitization. Biochim. Biophys. Acta 673: 454-466.

Visser, T. J., W. Klootwijk, R. Doctor, and G. Hennemann (1977) A different approach to the radioimmunoassay of thyrotropin-releasing hormone. In Radioimmunoassay and Related Procedures in Medicine 1977, pp. 469-477, National Atomic Energy Agency,Vienna.

von Euler, C., J. N. Hayward, I. Marttila, and R. J. Wyman (1973) Respiratory neurons of the ventrolateral nucleus of the solitary tract of cat: Vagal input, spinal connections and morphological identification. Brain Res. 61: 1-22.

Webber, C. L., Jr., R. D. Wurster, and J. M. Chung (1979) Cat phrenic nucleus architecture as revealed by horseradish peroxidase mapping. Exp. Brain Res. 35: 395-406.

White, S. R., and R. S. Neuman (1980) Facilitation of spinal motoneurone excitability by 5-hydroxytryptamine and noradrenaline. Brain Res. 188: 119-127.

Wiklund, L., L. Leger, and M. Persson (1981) Monoamine cell distribution in the cat brain stem. A fluorescence histochemical study with quantification of indolaminergic and locus ccruleus cell groups. J. Comp. Neurol. 203: 613-647.

Yamada, K. A., P. Hamosh, and R. A. Gillis (1981) Respiratory depression produced by activation of GABA receptors in hindbrain of cat. J. Appl. Physiol. 51: 1278-1286.

Yamada, K. A., W. P. Norman, P. Hamosh, and R. A. Gillis (1982) Medullary ventral surface GABA receptors affect respiratory and cardiovascular function. Brain Res. 248: 71-78.

Yamamoto, Y., H. Lagercrantz, and C. von Euler (1981) Effects of substance $\mathrm{P}$ and TRH on ventilation and pattern of breathing in newborn rabbits. Acta Physiol. Scand. 113: 541543 . 